\title{
Laparoscopic Radical Prostatectomy in Albania: Initial Experience in 25 Patients
}

\author{
Astrit Mustafaj ${ }^{1,3^{*}}$, Evisa Zhapa ${ }^{1}$, Francesco Saverio Grossi ${ }^{1,2}$
}

Received: 10 April 2018; Accepted: 30 June 2018; Published online: 20 July 2018. DOI; https://doi.org/10.32391/ajtes.v2i2.4

\footnotetext{
Abstract

Background: Laparoscopic or robotic assisted prostatectomy has become common world wide. However, to our knowledge, laparoscopic radical prostatectomy has not been reported in Albania.

Objective: To analyze the early perioperative and oncologic results obtained with the extraperitoneal laparoscopic prostatectomy (ELRP).

Patients and Method: A retrospective study of all the patients operated at Salus Hospital Tirana, Albania. All data were collected and evaluated retrospectively on the basis of thorough clinical and pathological examination. For data management and statistical analysis, all variables pre-, intra- and perioperative data were collected in a spreadsheet.

Results: In the 4-year period ( outline the period), 25 patients underwent the ELRP procedure. The average age of patients was 65 year-old and the PSA of $17.5 \mathrm{ng} / \mathrm{dl}$. The total surgery time was 168 minutes on average. Only one patient was transfused after surgery, and limfocele was present in 2 patients. No other complications occured.

Pathological examination revealed pT2 and pT3 cancers in $72 \%$ (18/25) and $25 \%$ (6/25) of patients, respectively. One patient had regional lymph nodes infiltration. The incidence of positive surgical margins and biochemical relapse rate was $16 \%(4 / 25)$ and $32 \%(8 / 25)$, respectively.

Conclusion: The ELRP technique is safe and effective procedure in the treatment of prostate cancer, with low morbidity.

Keywords: Laparoscopy; prostate cancer; radical prostatectomy

*Corresponding Author: Astrit Mustafaj

$\equiv \lambda$ Email: astritmustafaj@yahoo.com

${ }^{1}$ Urology Department, Italo-Albanian, "Salus" Hospital

2 Urology Department, Hospital SS Annunziata of Taranto.

${ }^{3}$ University Hospital of Trauma Tirana, Albania
} 


\section{Introduction}

Schuessler et al. (1) in 1992 introduced the laparoscopic approach for surgical treatment of prostate cancer, and Guillonneau and Vallancien (2) in 1999 standardized the technique, making it feasible and reproducible. Since then, the use of LRP has widely spread in throughout the world and, in some center has completely replaced the open prostatectomy. Many studies in the literature confirm the maturity of the laparoscopic technique: the results of oncological and functional outcomes are similar to those of traditional surgery, with all the advantages of minimal invasiveness. The Urological Department of Salus Hospital Tirana, Albania first carried out a laparoscopic radical prostatectomy (LRP) in 2013. In the present study, we report our results after 4 years of procedures, analyzing in particular the oncological and functional aspects.

\section{Patients and Methods}

Patients. Between September 2013 and December 2017, 25 patients with prostate cancer, underwent extraperitoneal (Figure 1) LRP at our Center.

All procedures were performed by three surgeons. Qualitative and quantitative data were assessed and analized.

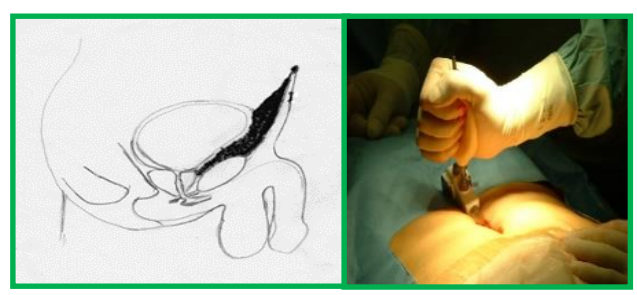

Figure 1
Preoperative data are summarized in Table 1.

\begin{tabular}{|l|l|}
\hline \multicolumn{2}{|c|}{ Preoperative data } \\
\hline $\begin{array}{l}\text { Number of patients } \\
\text { Age (years) (median } \\
\text { range) }\end{array}$ & $65(57-76)$ \\
\hline $\begin{array}{l}\text { PSAng/mL (median, } \\
\text { range) }\end{array}$ & $17,5(1-170)$ \\
\hline $\begin{array}{l}\text { Follow up months } \\
\text { (median, range) }\end{array}$ & $28(2-50)$ \\
\hline
\end{tabular}

Our criteria for performing a nerve-sparing procedure were: age and preoperative erectile function, absence of unilateral palpable nodule or involvement of the prostatic capsule at imaging, ipsilateral Gleason score $\leq 3+4$, Prostate Specific Antigen (PSA) $<10 \mathrm{ng} / \mathrm{ml}$.

At our Clinic, the staging lymph node dissection is done to all the patients.

Pathological examination. All prostate specimens were analized by a dedicated pathologist who reported the following features: Gleason score, [pre-International Society of Urological Pathology (ISUP) 2005 (3)], (Table 2) pathological stage, seminal vesicle invasion, extracapsular extension (defined as the presence of neoplastic cells into adipose tissue), surgical margin status (cancer at the margin marked with ink) and lymph node invasion.

Follow-up: recovery of continence, potency, cancer control. Patients were discharged with a program of follow-up visits at 1, 3, 6 and 12 months. The recovery of urinary continence was evaluated on the basis of the number of pads/day. 


\begin{tabular}{|l|l|}
\hline $\begin{array}{l}\text { Clinical Gleason } \\
\text { Score and Clinical } \\
\text { Stage }\end{array}$ & $\mathbf{N r}(\%)$ \\
\hline $\begin{array}{l}\text { Clinical Gleason } \\
\text { score }\end{array}$ & \\
\hline$<\mathbf{6}$ & $15(60)$ \\
\hline $\mathbf{3 + 4}$ & $4(16)$ \\
\hline $\mathbf{4 + 3}$ & $3(12)$ \\
\hline $\mathbf{8 - 1 0}$ & $2(8)$ \\
\hline & \\
\hline Clinical Stage & \\
\hline T1a, b & $4(16)$ \\
\hline T1c & $21(84)$ \\
\hline cT2 & 0 \\
\hline cT3 & 0 \\
\hline
\end{tabular}

Table 2

Patients free of pads were considered complete continent. The occasional loss of urine (one minipad per day) was classified as minimal stress incontinence. The use of two or more pads indicated moderate-tosevere incontinence. Good erectile function was defined as the ability to achieve an erection sufficient for penetration with or without the use of inhibitors of phosphodiesterase type 5 (PDE-5). Patients who reported erections only with intracavernous injection or vacuum devices were considered impotent. Biochemical relapse (BCR) was defined as a PSA value greater than $0.2 \mathrm{ng} / \mathrm{ml}$, increasing from previous values.

Data collection and statistical methodology.

All data were collected and evaluated retrospectively on the basis of thorough clinical and pathological examination. For data management and statistical analysis, all variables pre-, intra- and perioperative data were collected in a spreadsheet (Table 3)

\begin{tabular}{|l|r|}
\hline Perioperative data & \\
\hline $\begin{array}{l}\text { Operative time min } \\
\text { (range) }\end{array}$ & $168(110-$ \\
\hline Transfusion rate & $1(4 \%)$ \\
\hline $\begin{array}{l}\text { Conversion rate } \\
\text { Median cateterizatin time } \\
\text { (range) days }\end{array}$ & $9,8(6-15)$ \\
\hline $\begin{array}{l}\text { Mean hospital stay } \\
\text { (range) days }\end{array}$ & $6,4(3-12)$ \\
\hline $\begin{array}{l}\text { Lymph node metastasis } \\
\text { Table 3 }\end{array}$ & $1(4 \%)$ \\
\hline
\end{tabular}

\section{Results}

Pre-and perioperative clinical data. Most patients had a clinical Gleason score $\leq 6$ (60\%), while high-grade (4-6) disease accounting for only $8 \%$ of cases. At the time of surgery, all the 25 patients (100\%) had clinically-localized disease (T1-T2)

\begin{tabular}{|l|l|l|l|l|}
\hline $\begin{array}{l}\text { Pathological } \\
\text { Stage }\end{array}$ & $\mathbf{n r}$ & $\begin{array}{l}\text { Positive } \\
\text { Margins } \\
\text { R+ (\%) }\end{array}$ & $\begin{array}{l}\text { Clinical } \\
\text { Gleason } \\
\text { score }\end{array}$ & $\mathbf{N}(\%)$ \\
\hline T1a, b & 0 & 0 & $<6$ & $13(52)$ \\
\hline T1c & 1 & 0 & $3+4$ & $9(36)$ \\
\hline cT2 & 18 & $2(8)$ & $4+3$ & $1(4)$ \\
\hline cT3 & 6 & $2(8)$ & $8-10$ & $2(8)$ \\
\hline & & $\begin{array}{l}\text { Total } 4 \\
(16 \%)\end{array}$ & \\
\hline
\end{tabular}

Table 4 
An extraperitoneal approach was performed in all the patients. of the patients needed intensive care recovery after surgery.

\section{Discussion}

Pathological outcome and oncological follow-up. Pathological characteristics are summarized in Table 4.

The follow-up ranged from 2 to 50 months (median $=28$ months). The overall BCR rate was $32 \%(8 / 25)$ (Table 5$)$.

\begin{tabular}{|l|l|}
\hline $\begin{array}{l}\text { Biochemical Relapse. } \\
\text { Stage and Gleason Score }\end{array}$ & tot $8(32 \%)$ \\
\hline Pathological stage (nr) & $\begin{array}{l}\text { Pathological } \\
\text { Gleason Score }\end{array}$ \\
\hline pT2 (3) & $<6(1)$ \\
\hline pT3a (2) & $3+4(4)$ \\
\hline pT3b (3) & $4+3(1)$ \\
\hline & $8-10(2)$ \\
\hline
\end{tabular}

Table 5

None of the patients developed bone metastases or died from prostate cancer desease or other deseases.

\section{Functional outcome.}

Urinary continence: The rate of minimal stress incontinence is $40 \%(10 / 25)$ and no one has moderate-to-severe incontinence.

Erectile function: We have no data about erectile function.

Complications. Overall, we recorded 2 patients complicated by limphocele in 25 LRPs (8\%). No one needed re-operation as both were absorbed spontaneously. None
Oncological outcome. The cornerstones that have guided the development of LRP are maintaining quality of life, good oncological control, low morbidity, and the benefits of a minimally, invasive approach. A magnified view and the consequent better appreciation of the anatomical structures are closely linked to the achievement of these goals. Among them, the primary objective is to control cancer. Experience with the Heilbronn technique on 500 patients led to an overall postive margin rate of $19 \%$ ( $7.4 \%$ and $31.8 \%$ in pT2 and pT3 cases, respectively) (4). The experience on 1000 patients at the Charité Hospital in Berlin was as follows: $14.8 \%$ in pT 2 and $54.4 \%$ in pT3 cases (5). In a series of 1,300 patients, the University of Leipzig reported a positive margin rate of $9.8 \%$ in $\mathrm{pT} 2$ and $34.3 \%$ in pT3 cases (6). Overall, considering the data reported in the most important series of LRP, the rate of positive surgical margins in LRP ranges from $11 \%$ to $30 \%$ (7).

In our study, positive surgical margins were identified in $16 \%$ of patients $(4 / 25)$, in particular, in $8 \%$ of pT2 and in $8 \%$ of pT3 cases.

Regarding the evaluation of biochemical progression, different series use different PSA cut-offs in the definition of relapse, which vary from 0.1 to $0.4 \mathrm{ng} / \mathrm{ml}$. Recently Hruza et al. published long-term oncological 
results: the BCR-free survival rate 10 years after LRP was $80.2 \%$ in pT2, $47.4 \%$ in pT3a and $49.8 \%$ in $\mathrm{pT} 3 \mathrm{~b} / \mathrm{pT} 4$ cases, confirming a better prognosis in patients with organconfined disease $(p<0.001)$ (8). The rate of clinical progression-free survival at 10 years were: $97.2 \%$ in pT2, $84.4 \%$ in pT3a and $78.1 \%$ in $\mathrm{pT} 3 \mathrm{~b} / \mathrm{pT} 4$ cases, and estimates of cancer-specific survival were 100\%, 97.3\% and $90.6 \%$, respectively.

In our series, the BCR-free survival at 3 years is $68 \%$,

The major series report $94.4 \%$ of BCR-free survival at 3 years from LRP. Functional outcome. Functional results (urinary continence and erectile function) are becoming increasingly important for many patients. One of the main advantages of a minimally-invasive approach is the control of bleeding. The magnified view and better hemostasis allow for accurate identification of the different anatomical and functional structures and, accordingly, a more respectful surgery.

The main problem, which can make any objective comparative analysis between the different series impossible, is the lack of uniformity in defining, evaluating and reporting functional outcomes after radical prostatectomy. This usually leads to a great variability in the results of the different published series.

In our experience, at a timepoint of at least 12 months after surgery, $15 / 25$ patients (60 $\%)$ were completely continent, 10/25 (40\%) reported minimal stress incontinence (one mini pad), no patients needed more than one pad.
Similarly, the erectile function recovery rate varies significantly in different reports as there is no consensus regarding the definition, the use of different data collection methods and the use of drugs for the treatment of impotence. In literature, important prognostic factors for predicting a good recovery of erectile function are: patient's age, preoperative function, nerve-sparing technique, and duration of follow-up (9). The majority of series report data on small groups of patients, usually treated after the surgical technique was well-acquired (10). Stolzenburg et al., using the IIEF, reported their experience of 700 extra-peritoneal LRPs: follow-up was 6 months and a nervesparing technique was performed in 185 (26.4\%) patients, potent before surgery, unilaterally in 114 patients (16.2\%) and bilaterally in 71 (10.1\%) (11). At 6 months, 8 out of 66 men with unilateral technique (12.1\%) and 16 of 34 with bilateral sparing (47.1\%) had erections sufficient for intercourse with or without the help of PDE5 inhibitors. Rassweiler et al. reported the results of their first 180 LRP in 2003: 10 patients were treated with nerve-sparing technique (two bilateral and eight unilateral). Four patients had erections sufficient with sildenafil (12). The Montsouris group reported functional data of 47 consecutive patients under the age of 70 years, potent before surgery and treated with bilateral nerve-sparing LRP: 31 (66\%) of those were able to have intercourse with or without PDE5 (13). In our series, we have no certain data on potency. This is due to the fact that our patents do not refere during the follow-up 
visits about erectile function as they retain as primary end-point the oncological safety, secondly the preservation of urinary continence, and the erectile function not important. However we do not have patients who use intra-cavernous injections or vacuum devices.

Perioperative outcome. In literature, the only proven advantages of LRP over the open technique are reduced blood loss, transfusion rates, hospital stay, postoperative pain, and duration of catheterization (14). The average blood loss reported after LRP ranges between 200 and $390 \mathrm{ml}$. The Montsouris group reported an average blood loss of $380 \mathrm{ml}$ and a transfusion rate of $4.9 \%$. In our experience we transfused only one patient over 25 operated.

The data on the length of hospital stay are extremely variable and must be interpreted in the light of the economic differences of health systems in Europe and the USA. In the USA, the patient is discharged very quickly, in $90 \%$ of cases within the second day (15). The main non-comparative studies indicate a range of hospitalization between 2 and 10 days, while the duration of catheterization is 7-10 days. Several reference Centers prefer to remove the catheter around the sixth to seventh postoperative day. At our Clinic, the average duration of catheterization was 9.8 days. We remove the catheter after a retrograde cystography.

\section{Conclusion}

Four years after the first LRP performed at our Clinic, the first series reported in
Albania, we can state that Laparoscopic radical prostatectomy is a a safe and effective procedure in the treatment of prostate cancer, with low morbidity. We do not perform open surgery for prostate cancer, and we can say that the "gold standard" in our hand is Laparoscopic radical prostatectomy for prostate cancer. In our experience, the benefits are all related to the less invasive approach: reduced hospital stay, blood loss and pain, with improved recovery and cosmesis. The major difficulty is overcoming a learning curve that may seem prohibitive. However, with increasing experience and thanks to technological advances, the true potential of laparoscopy is gradually emerging.

\section{References}

1. Schuessler WW, Kavoussi LR, Clayman RV and Vancaille TH: Laparoscopic radical prostatectomy: Initial case report (abstract 130). J Urol 147: 246A, 1992.

2. Guillonneau B and Vallancien G: Laparoscopic radical prostatectomy: the Montsouris technique. J Urol 163: 16431649, 2000.

3. Epstein JI, Allsbrook WC Jr., Amin MB, Egevad LL; ISUP Grading Committee: The 2005 International Society of Urological Pathology (ISUP) Consensus Conference on Gleason Grading of Prostatic Carcinoma. Am J Surg Pathol 29(9): 1228- 1242, 2005.

4. Rassweiler J, Schulze M, Teber D, Marrero R, Seemann O, Rumpelt J and Frede T: Laparoscopic radical prostatectomy with the Heilbronn technique: oncological results in the first 500 patients. J Urol 173(3): 761-764, 2005. 
5. Lein M, Stibane I, Mansour R, Hege C, Roigas J, Wille A, Jung K, Kristiansen $G$, Schnorr D, Loening SA and Deger S: Complications, urinary continence, and oncologic outcome of 1000 laparoscopic transperitoneal radical prostatectomiesexperience at the Charite Hospital Berlin, Campus Mitte Eur Urol 50(6): 1278- 1282, 2006.

6. Stolzenburg JU, Rabenalt R, Do M, Truss MC, Burchardt M, Herrmann TR, Schwalenberg T, Kallidonis $\mathrm{P}$ and Liatsikos EN: Endoscopic extraperitoneal radical prostatectomy. The University of Leipzig experience of 1,300 cases. World J Urol 25: 45-51, 2007.

7. Ficarra V, Novara G, Artibani W, Cestari A, Galfano A, Graefen M, Guazzoni G, Guillonneau B, Menon M, Montorsi F, Patel $\mathrm{V}$, Rassweiler J and Van Poppel H: Retropubic, laparoscopic, and robotassisted radical prostatectomy: a systematic review and cumulative analysis of comparative studies. Eur Urol 55: 10371063, 2009.

8. Hruza M, Bermejo JL, Flinspach B, Schulze M, Teber D, Rumpelt HJ and Rassweiler JJ: Long-term oncological outcomes after laparoscopic radical prostatectomy BJU Int Feb 2: 271-280, 2013.

9. Hoznek A, Menard Y, Salomon L and Abbou CC: Update on laparoscopic and robotic radical prostatectomy Current Opinion in Urology 15: 173-180, 2005.
10. Goeman L, Salomon L, La De Taille A, Vordos D, Hoznek A, Yiou R and Abbou CC: Long-term functional and oncological results after retroperitoneal laparoscopic prostatectomy according to a prospective evaluation of 550 patients World J Urol Aug 24(3): 281-288, 2006.

11. Stolzenburg JU, Rabenalt R, DO M, Ho K, Dorschner W, Waldkirch E, Jonas U, Schütz A, Horn L and Truss MC: Endoscopic extraperitoneal radical prostatectomy: oncological and functional results after 700 procedures: J Urol 174: 1271- 1275, 2005. 12. Rassweiler J, Seemann O, Hatzinger M, Schulze $M$ and Frede $T$ : Technical evolution of laparoscopic radical prostatectomy after 450 cases. J Endourol 17: 143, 2003.

13. Guillonneau B, Cathelineau X, Doublet JD Baumert $\mathrm{H}$ and Vallancien $\mathrm{G}$ :

Laparoscopic radical prostatectomy: assessment after 550 procedures. Crit Rev Oncol Hematol 43: 123, 2002.

14. Touijer K and Guillonneau B:

Laparoscopic radical prostatectomy: a critical analysis of surgical quality Eur Urol 49: 625- 632, 2006.

15. Lepor H and Kaci L: Contemporary evaluation of operative parameters and complications related to open radical retropubic prostatectomy. Urology 62(4): 702-706, 2003. 